\title{
PREPARATION OF VEIN GRAPHITE ANODE MATERIALS BY ECO-FRIENDLY MILD OXIDATION, FOR LITHIUM-ION RECHARGEABLE BATTERIES
}

\author{
T.H.N.G. AMARAWEERA ${ }^{1 *}$, S. PYNTHAMIL ${ }^{1}$, H.W.M.A.C. WIJAYASINGHE ${ }^{2}$, \\ N.W.B. BALASOORIYA ${ }^{3}$ \\ ${ }^{1}$ Faculty of Science and Technology, Uva Wellassa University, Sri Lanka \\ ${ }^{2}$ National Institute of Fundamental Studies, Kandy, Sri Lanka \\ ${ }^{3}$ Department of Geology, University of Peradeniya, Sri Lanka \\ *Corresponding author e-mail: gayani@uwu.ac.lk
}

(Received $21^{\text {st }}$ June 2019; accepted $4^{\text {th }}$ October 2019)

\begin{abstract}
Vein graphite with high purity and crystallinity has been identified as a cost-effective source to produce anode material. High anisotropy of graphite surface and impurities in trace levels cause profound alteration of electrochemical activities in Lithium-ion Rechargeable Batteries (LIBs). Surface modification with strong chemical oxidant such as $\left(\mathrm{NH}_{4}\right)_{2} \mathrm{~S}_{2} \mathrm{O}_{8}, \mathrm{HNO}_{3}$ and $\mathrm{HF}$, which are highly toxic and hazardous is identified as a successful method to modify the graphite as an anode material. Therefore, an eco-friendly approach to modify the vein graphite surface was investigated in this study. Purified needle platy graphite was treated with $\mathrm{H}_{2} \mathrm{O}_{2}$ solution at $60^{\circ} \mathrm{C}$ for 24 hours. FT-IR spectra and Powder X-ray diffraction (PXRD) patterns oxidized graphite indicate the formation of acidic groups or an oxidized layer without affecting the crystallographic structure of graphite due to mild oxidation with $\mathrm{H}_{2} \mathrm{O}_{2}$. In addition, Thermogravimetric Analysis (TGA) and Scanning Electron Microscopic (SEM) images provided results suggesting that the oxidation eliminates some reactive structural defects in vein graphite. The electrochemical properties of the graphite electrodes were studied with the assembled CR 2032 coin cells. The charge, discharge study of the assembled cells, carried out at $\mathrm{C} / 5$ rate with a cutoff voltage of $0.002-1.5 \mathrm{~V}$ at room temperature indicate a considerable improvement in the overall electrochemical performance of the graphite electrode material prepared by mild oxidation using $\mathrm{H}_{2} \mathrm{O}_{2}$ as the oxidant. This enhancement of electrochemical performance may results due to the improved graphite surface structure formed by the $\mathrm{H}_{2} \mathrm{O}_{2}$ mild oxidation process used in this study. Mild oxidation of vein graphite with $\mathrm{H}_{2} \mathrm{O}_{2}$ is ecofriendly and cost- effective method since water is the by-product of the oxidation process carried out at low temperature.
\end{abstract}

Keywords: Vein Graphite, Surface Modification, Lithium Ion Battery. Eco-Frieldly

\section{INTRODUCTION}

Lithium-ion Rechargeable Batteries (LIBs) have been identified as a very reliable and most promising power source and especially used in hybrid vehicles and portable electronic devices. In addition to other advantages, Lithium-ion battery avoids the environmental problems associated with the heavy metals $(\mathrm{Pb}, \mathrm{Cd}$ and $\mathrm{Ni})$ used in traditional rechargeable batteries (Kurzweil, 2009). However, anode materials used in commercial LIBs use graphitic carbon produced by high temperature $\left(>2000^{\circ} \mathrm{C}\right)$ process that release greenhouse gasses such as 
$\mathrm{CO}, \mathrm{CO}_{2}$ and $\mathrm{C}_{\mathrm{x}} \mathrm{H}_{\mathrm{y}}$ (Wissler, 2006). In this contest, natural vein graphite has identified as an effective anode material for LIBs due to high abundance. However, natural graphite can not be directly used as anode material due to poor electrochemical performance (Fu et al., 2006). The poor electrochemical performance resulted due to electrolyte decomposition, solvent cointercalation and movement of the graphene layers along the a-axis direction during the intercalation and de-intercalation ( $\mathrm{Fu}$ et al., 2006).

Among the natural graphite, vein graphite in Sri Lanka is well-known for its high purity and the crystalline structure (Balasooriya et al., 2006). Vein graphite in Sri Lanka have been categorized into four common structurally distinct morphological graphite varieties; shinyslippery-fibrous graphite (SSF), needle-platy graphite (NPG), coarse striated-flaky graphite (CSF) and coarse flakes of radial graphite (CFR) (Touzain et al., 2010). Studies showed that mechanically attached and intercalated impurities associated with vein graphite surface can effectively be removed by treating with 520 vol. $\% \mathrm{HCl}$ solution at $60-65^{\circ} \mathrm{C}$ depending on initial purity of different structural varieties (Amaraweera et al., 2013). Further, mild oxidation is effective in removing reactive defects such as $\mathrm{sp}^{3}$-hybridized carbon atoms, carbon-chain and carbon radicals of graphite structure (Fu et al., 2006). This improves the surface structure of graphite. More importantly, a dense layer of an oxide such as carbonyl, carboxyl and hydroxyl form on the edge plane of graphite due to mild oxidation process ( $\mathrm{Wu}$ et al., 2003, Badenhorst and Focke, 2013). During the first charge of LIB, this dense layer of oxide becomes part of the Solid Electrolyte Interface (SEI). The SEI is a complex passivation layer, electronically insulate but ionically conductive, formed on individual graphite particles of the negative electrode. The potential difference across the SEI layer during charging results in the potential for $\mathrm{Li}^{+}$intercalation at the graphiteSEI interface to be lower than the potential at the SEI-electrolyte interface (Buqa et al., 2006). This prevents electrolyte reduction and decomposition. The SEI film also protects the graphite anode from solvent co-intercalation which, for some solvent causes detrimental exfoliation of the graphite (Menachem et al., 1998; Badenhorst and Focke, 2013). Consequently, the composition, the stability as well as the compactness of the SEI are very important in determining the electrochemical performance.

Use of strong chemical oxidants such as $\left(\mathrm{NH}_{4}\right)_{2} \mathrm{~S}_{2} \mathrm{O}_{8}, \mathrm{HNO}_{3}$ and $\mathrm{HF}$ is identified as a successful method for surface modification of natural graphite (Ein-Eli and Koch, 1997; Wu et al., 2002, 2003; Xiaowei et al., 2004; Balasooriya et al., 2006; $\mathrm{Fu}$ et al., 2006; Amaraweera et al., 2014, 2018; Hewathilake et al., 2017). Those strong chemicals are hazardous and highly toxic substances. Mild oxidation with $\mathrm{H}_{2} \mathrm{O}_{2}$ is much more environmentally friendly since the only by-product is water (You et al., 2017). In this study, $\mathrm{H}_{2} \mathrm{O}_{2}$ is used as an oxidant to mildly oxidize the Sri Lankan vein graphite due to its environment-friendly nature and low cost.

\section{MATERIALS AND METHODS}

\section{Material Synthesis}

The Needle-Platy Graphite (NPG), which is characterized by the layered like feature, smooth surface and non-continuous needles on the surface were collected from a graphite mine by visual inspection. NPG was selected for this study since it has the highest natural carbon content compared to all other morphological vein graphite varieties (Amaraweera et al., 2013). Vein graphite was crushed into a fine powder using vibratory disc mill for about 3 to 4 minutes and powder fraction $(<53 \mu \mathrm{m})$ was separated using a mechanical sieve. Samples were purified by acid leaching purification (Amaraweera et al., 2013, 2017). Purified vein graphite samples were mildly oxidized with $30 \%$ $\mathrm{H}_{2} \mathrm{O}_{2}$ (Research-lab fine Chem industries) solution at a constant temperature of $60^{\circ} \mathrm{C}$ for 24 hours. Then, the vein graphite slurry was separated by filtration and the filtered sample 
was washed with distilled water until it neutralized. Then the sample powder was dried at $110^{\circ} \mathrm{C}$ for 24 hours.

\section{Material Characterization}

Powder X-ray diffraction (PXRD, Siemens D5000) using $\mathrm{CuK} \alpha$ radiation were used to identify the effect of surface modification of the graphite structure. Scanning electron microscopy (SEM, FEI Quanta 200 FEGESEM) was engaged to observe effects of surface modification morphology of graphite. Thermogravimetry analyses (TGA) of raw and treated graphite were carried out on a PerkinElmer TGS-2 Thermogravimetric System to study the thermal behavior. The thermogravimetric measurements were taken between room temperature and $800^{\circ} \mathrm{C}$, under a nitrogen atmosphere. Fourier Transform Infrared Spectroscopy (FT-IR) was used to analyze the surface structure of purified and surface modified graphite. Constant-weight $\mathrm{KBr}$ pellets with $1.0 \mathrm{~cm}$ diameter were prepared by $\mathrm{KBr}$ and sample into ratio of 100:1 for the IR measurement. The spectra were measured in the $400-4000 \mathrm{~cm}^{-1}$ region for absorption mode with a Nicolet 6700 FT-IR spectrophotometer.

The graphite powder was uniaxially pressed at $100 \mathrm{MPa}$ to prepare solid pellets of $12 \mathrm{~mm}$ diameter and $0.75 \mathrm{~cm}$ length. The pellet was directly sandwiched between two platinum electrodes in a sample holder. The d.c. fourprobe electrical conductivity measurements were performed on the pellets.

\section{Electrochemical Analysis}

Electrodes were prepared by casting a mixture of $90 \%$ of active material (developed vein graphite) $15 \%$ of PvDF (KynarFlex 2801) binder together with acetone (Sigma Aldrich) solvent on a copper current collector. Coin Cells (CR 2032) were assembled in an Argon-filled glove-box (Lab Start 50), in which moisture and oxygen were automatically controlled to be less than $1 \mathrm{ppm}$.
In order to study the electrochemical properties of the prepared graphite electrode materials, lithium foil (Sigma Aldrich) used as a standard counter and reference electrode for all test cells. Circular disks of $12 \mathrm{~mm}$ diameter and around $100 \mu \mathrm{m}$ thickness, punched from the fabricated electrodes, were used as working electrodes. The electrolyte was $1 \mathrm{M}$ LiPF6 in ethylene carbonate and diethyl carbonate (1:1 ratio in weight). Microporous membranes, Cellgard 2400 were used as a separator. The separator was soaked with the electrolyte solution for fabricating the test cell. Finally, the charge-discharge study of the assembled cells was carried out at $\mathrm{C} / 5$ rate with a cutoff voltage of $0.002-1.5 \mathrm{~V}$ at room temperature using a Metrohm Auto Lab (PGSTAT302N) controlled by Nova 1.1 program.

\section{RESULTS AND DISCUSSION}

\section{Surface Modification of Vein Graphite}

FT-IR spectra of NPG variety of vein graphite before and after the mild oxidation are shown in Fig 1. The vibrational bands correspond to $v_{\mathrm{C}=\mathrm{O}}$ stretching at $1720-1680 \mathrm{~cm}^{-1}$, $v_{\mathrm{O}-\mathrm{H}}$ stretching at $1360 \mathrm{~cm}^{-1}$ and $v_{\mathrm{C}-\mathrm{O}}$ stretching at $1260-1000 \mathrm{~cm}^{-1}$ are predominant in the mildly oxidized graphite surface (Ein-Eli and Koch, 1997). These bands are very similar to those published in earlier (Amaraweera et al., 2014, 2018). Therefore, the FT-IR spectra of four morphological varieties confirm the formation of acidic groups or an oxidized layer on the surface of vein graphite after the mild oxidation with $\mathrm{H}_{2} \mathrm{O}_{2}$.

The intensity of absorption peaks representing carbonyl groups and $\mathrm{C}-\mathrm{O}$ acid group of mildly oxidized vein graphite with $\mathrm{H}_{2} \mathrm{O}_{2}$ is relatively weak compared to that of mild oxidized vein graphite with $\left(\mathrm{NH}_{4}\right)_{2} \mathrm{~S}_{2} \mathrm{O}_{8}$ (Amaraweera et al., 2013, 2014, 2018). This may be due to the weak oxidation ability of $\mathrm{H}_{2} \mathrm{O}_{2} \quad\left(\mathrm{E}_{0}=1.7 \mathrm{~V}\right)$ compared to $\left(\mathrm{NH}_{4}\right)_{2} \mathrm{~S}_{2} \mathrm{O}_{8}$ $\left(\mathrm{E}_{0}=2.1 \mathrm{~V}\right)$. 


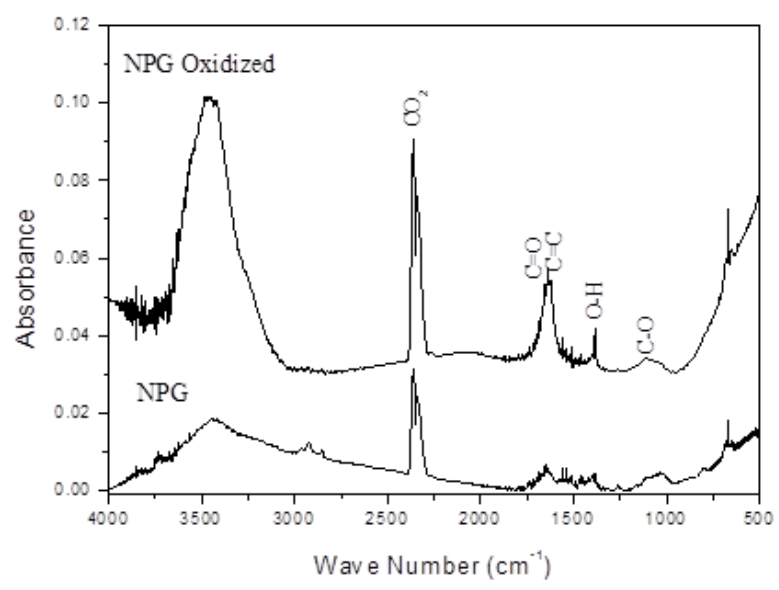

Fig. 1. FT-IR spectra of the purified NPG before and after mild oxidation with $\mathrm{H}_{2} \mathrm{O}_{2}$

Fig. 2 shows the PXRD patterns obtained on NPG graphite and NPG graphite powders after surface modification with $\mathrm{H}_{2} \mathrm{O}_{2}$. The major crystallographic peaks of graphite, corresponding to (002) and (004) are appeared prominently in this diffractogram (JCPDS: 751621). The diffractograms clearly indicate that the mild chemical oxidation of the graphite power with $\mathrm{H}_{2} \mathrm{O}_{2}$ did not affect the crystallographic structure of NPG graphite powder.

As shown in Fig. 2, the purely hexagonal structure of graphite samples could be maintained during the oxidation reaction with $\mathrm{H}_{2} \mathrm{O}_{2}$ similar to other strong chemical oxidants such as $\left(\mathrm{NH}_{4}\right)_{2} \mathrm{~S}_{2} \mathrm{O}_{8}, \mathrm{HNO}_{3}$ and $\mathrm{HF}$ (Ein-Eli and Koch, 1997; Wu et al., 2002, 2003; Xiaowei et al., 2004; Balasooriya et al., 2006; Fu et al., 2006; Amaraweera et al., 2014, 2018; Hewathilake et al., 2017). Further, mild oxidation process did not involve the formation of an intermediary graphite intercalation compound or other secondary phases (JCPDS: 75-1621). The rhombohedral phase content, $\left((101)_{\mathrm{R}} /(101)_{\mathrm{H}}\right.$ intensity ratio $\left.(\%)\right)$ of the purified NPG (13\% Rd) and mild oxidized NPG (13\% $\mathrm{Rh}$ ) remain almost constant after the chemical oxidation. Therefore, it is possible to receive the same electrochemical properties of a graphite powder after the mild oxidation with $\mathrm{H}_{2} \mathrm{O}_{2}$.

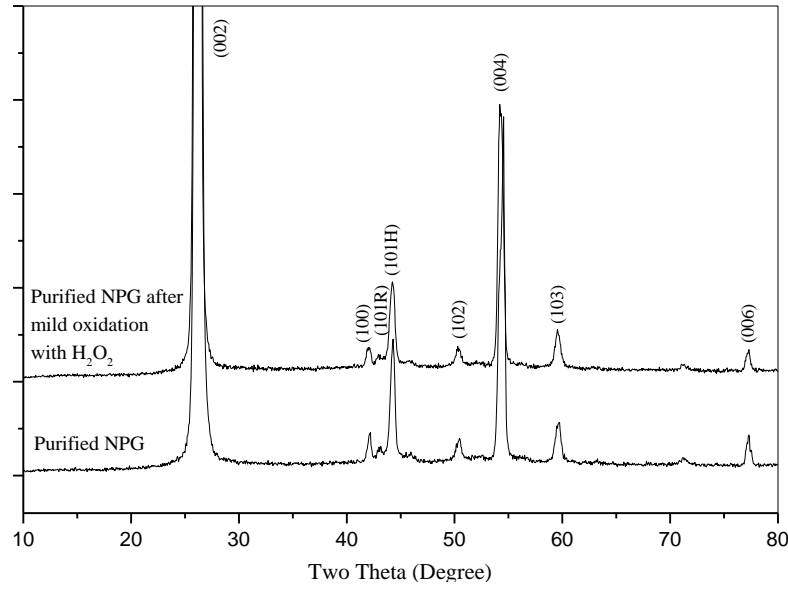

Fig. 2. The X-ray diffractograms obtained on purified NPG graphite and purified NPG graphite powders after mild oxidation with $\mathrm{H}_{2} \mathrm{O}_{2}$.

The scanning electron micrographs for purified NPG graphite and NPG graphite mildly oxidized with $\mathrm{H}_{2} \mathrm{O}_{2}$ are shown in Fig. 3. The basal plane of the purified NPG graphite oxidized with $\mathrm{H}_{2} \mathrm{O}_{2}$ shows a more reduced surface roughness compared to that of purified NPG (Wu et al., 2003).

Thermogravimetric analysis was also used to investigate the effect of mild oxidation of purified NPG. Fig. 4 shows the TGA of the purified NPG before and after the mild oxidation with $\mathrm{H}_{2} \mathrm{O}_{2}$. At first, the weight decreased slowly because of thermal decomposition of some oxides and slight oxidation under air including the removal of a small amount of absorbed water. Later, when the temperature arrived at about $500^{\circ} \mathrm{C}$, combustion began. TGA results suggest that the temperature at which combustion began increased after mild oxidation with $\mathrm{H}_{2} \mathrm{O}_{2}$ compared to purified NPG. The more reactive component in the carbon will oxidize at lower ignition temperature ( $\mathrm{Wu}$ et al., 2002; Xiaowei et al., 2004). Therefore, mild chemical oxidation leads to a stabilization of the graphite structure due to elimination of some reactive structural imperfections at the graphite surface (Wu et al., 2002, 2003). Since the reactive structural imperfections removed, temperature of combustion started shifting to higher temperatures after mild oxidation treatments. 


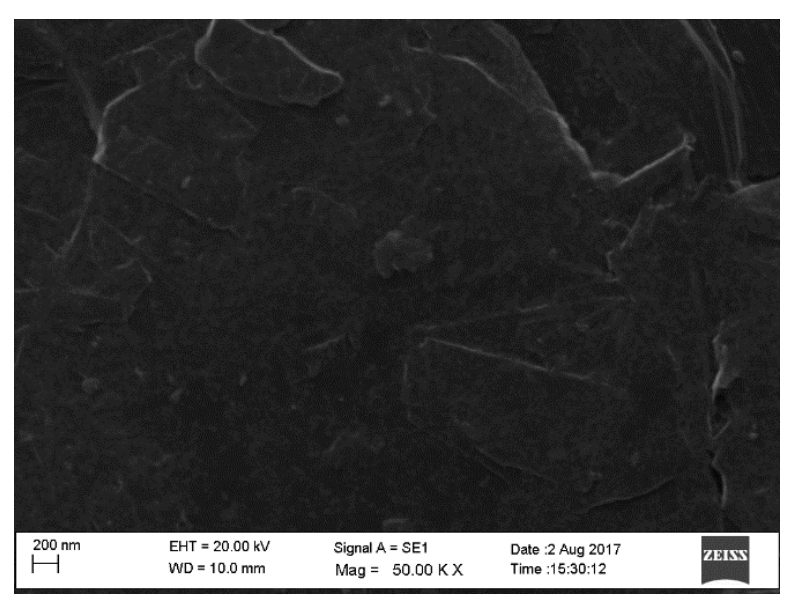

(a)

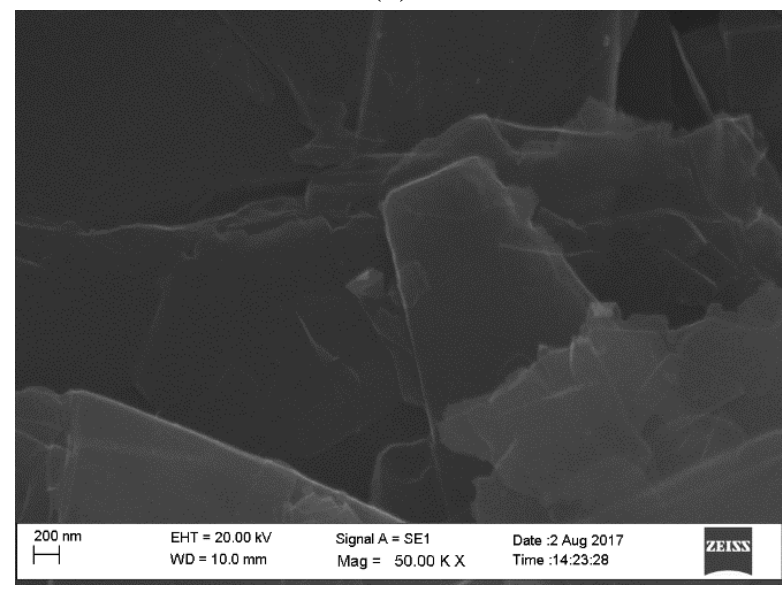

(b)

Fig. 3. SEM image of the of (a) purified NPG and (b) mild chemically oxidized NPG with $\mathrm{H}_{2} \mathrm{O}_{2}$

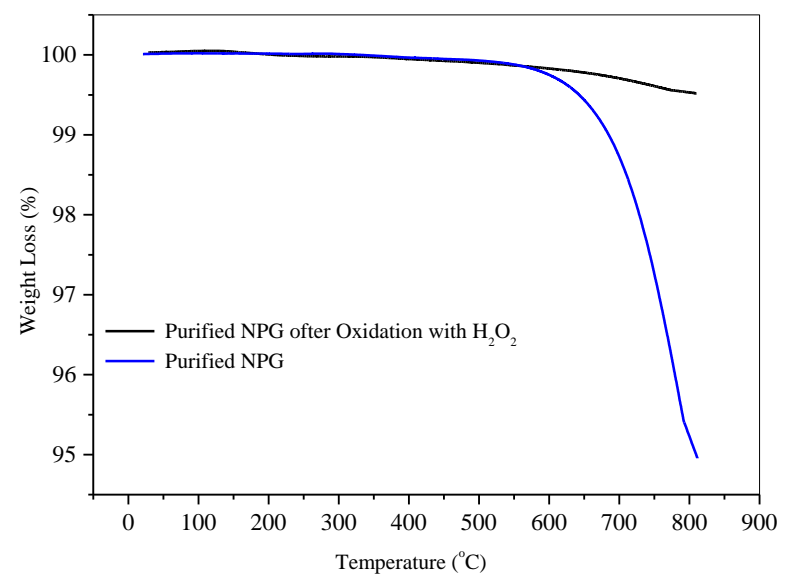

Fig. 4. Thermogravimetric plot of purified NPG and oxidized NPG after mild oxidation with $\mathrm{H}_{2} \mathrm{O}_{2}$

The d.c electrical conductivity of dense pellet prepared using four morphological varieties of graphite powder is given in Table 1.
Mild oxidation has not caused any adverse effect on the electronic properties of graphite (Amaraweera et al., 2018). This resultant conductivity is sufficient for the anode application in LIB.

Table 1: The electrical conductivity of NPG.

\begin{tabular}{lc}
\hline Graphite & $\begin{array}{c}\text { d.c Conductivity } \\
\left(\mathbf{S c m}^{-\mathbf{1}}\right)\end{array}$ \\
\hline Raw graphite & 1.9 \\
Purified graphite & 1.8 \\
$\begin{array}{l}\text { Oxidized } \\
\text { graphite }\end{array}$ & 1.2 \\
\hline
\end{tabular}

\section{Electrochemical Performance}

Thermogravimetric analysis, studies of surface morphology by scanning electron micrographs and surface analysis by FT-IR measurements imply that the chemical oxidation with $\mathrm{H}_{2} \mathrm{O}_{2}$ effectively modifies the graphite surface structure. The modification of graphite surface resulted by the eco-friendly approach in the present study is quite similar to the modification by highly toxic and hazardous strong chemical oxidants such as $\left(\mathrm{NH}_{4}\right)_{2} \mathrm{~S}_{2} \mathrm{O}_{8}, \mathrm{HNO}_{3}$ and $\mathrm{HF}$ (Balasooriya et al., 2006; Hewathilake et al., 2017; Amaraweera et al., 2018). Therefore, the electrochemical performance of purified NPG and chemically oxidized NPG with $\mathrm{H}_{2} \mathrm{O}_{2}$ was studied.

The initial discharge capacity of purified NPG was $472 \mathrm{~mA} \mathrm{~h} \mathrm{~g}^{-1}$ with an irreversible capacity of $127 \mathrm{mAhg}^{-1}$ and coulombic efficiency of $73 \%$. For cells with purified NPG by chemical oxidation with $\mathrm{H}_{2} \mathrm{O}_{2}$, the discharge capacity was $427 \mathrm{~mA} \mathrm{~h} \mathrm{~g}^{-1}$ with an irreversible capacity of $65 \mathrm{~mA} \mathrm{~h} \mathrm{~g}^{-1}$ and coulombic efficiency of $85 \%$. As indicated in TGA and SEM analysis, some reactive structural imperfections were eliminated effectively during the chemical oxidation. In addition, the surface of NPG was covered with a fresh and dense layer of oxides mainly 
hydroxyl/phenol, ether and ester as indicated by the FT-IR data of chemically oxidized graphite. This layer acted as a part of SEI when lithium intercalated and blocked the co-intercalation of solvated $\mathrm{Li}^{+}$(Wu et al., 2002; Fu et al., 2006; Placke et al., 2012). As a result the couombic efficiency increased and irreversible capacity decreased after the chemical oxidation with $\mathrm{H}_{2} \mathrm{O}_{2}$.

The initial discharge capacity of $345 \mathrm{~mA} \mathrm{~h}$ $\mathrm{g}^{1}$ with the coulombic efficiency of $94 \%$ was reported for mildly oxidized NPG with $\left(\mathrm{NH}_{4}\right)_{2} \mathrm{~S}_{2} \mathrm{O}_{8}$ (Amaraweera et al., 2018). NPG mild oxidized with HF showed an initial discharge capacity of $378 \mathrm{~mA} \mathrm{~h} \mathrm{~g}^{-1}$ with high columbic efficiency of over $99.9 \%$ (Hewathilake et al., 2017). This study resulted in the initial discharge capacityof $472 \mathrm{mAhg}^{-1}$ coulombic efficiency of $73 \%$. This implies that the mildly oxidized NPG with $\mathrm{H}_{2} \mathrm{O}_{2}$ has high potential as an active anode material for LIBs.

Fig. 5 shows the cycling behavior of purified and oxidized NPG (purified) with $\mathrm{H}_{2} \mathrm{O}_{2}$ at $\mathrm{C} / 5$ rate. The purified NPG has the highest initial discaharge capacity than mildly oxidized NPG. But after the second cycle, purified NPG showed quick capacity fading and mildly oxidized NPG showed a stable pattern. Electrochemical test analysis showed that the mildly oxidized graphite electrode shows better electrochemical performance when compared to purified graphite.

A previous study has shown that the discharge capacity faded from $345 \mathrm{~mA} \mathrm{~h} \mathrm{~g}^{-1}$ to $309 \mathrm{~mA} \mathrm{~h} \mathrm{~g}^{-1}$ over the first ten cycles for the chemically oxidized NPG (purified) sample with the strong oxidative agent, $\left(\mathrm{NH}_{4}\right)_{2} \mathrm{~S}_{2} \mathrm{O}_{8}$ (Amaraweera et al., 2018). Further, Hewathilake et al., 2017 reported higher discharge capacity (378 $\mathrm{mA} \mathrm{h} \mathrm{g}^{-1}$ ) without considerable fading during fifty cycles for the chemically oxidized NPG (purified) sample with HF. In this preliminary study the discharge capacity faded from $427 \mathrm{~mA} \mathrm{~h} \mathrm{~g}^{-1}$ to $330 \mathrm{~mA} \mathrm{~h}$ $\mathrm{g}^{-1}$ over the first six cycle for NPG (purified) mildly oxidized with $\mathrm{H}_{2} \mathrm{O}_{2}$. Even though the NPG (purified) mildly oxidized with $\mathrm{H}_{2} \mathrm{O}_{2}$ shows an irreversible capacity of $127 \mathrm{~mA}$ $\mathrm{h} \mathrm{g}^{-1}$ during the first cycle, the capacity fading is relatively low after the second cycle (Fig. 5). Hence, the NPG (purified) mildly oxidized with $\mathrm{H}_{2} \mathrm{O}_{2}$ will be a potential candidate as an anode material for LIB applications.

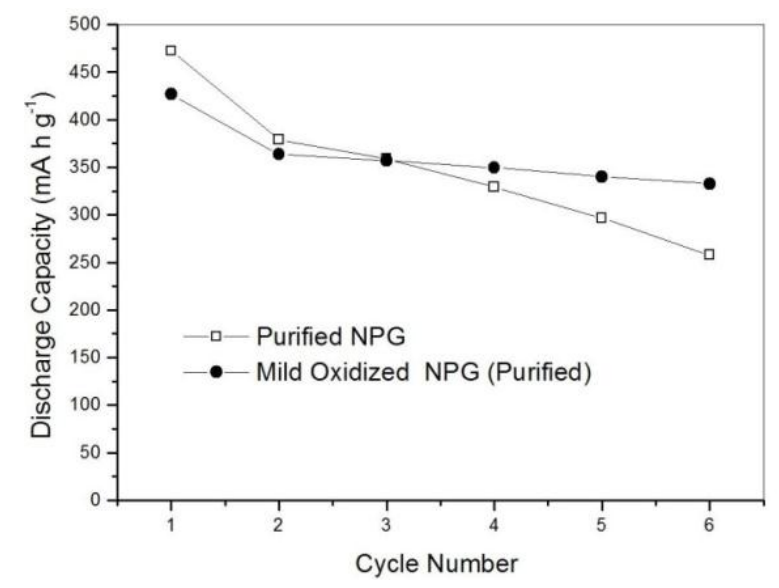

Fig. 5. Cycling behavior of purified $N P G$ and mild oxidized $\mathrm{NPG}$ with $\mathrm{H}_{2} \mathrm{O}_{2}$ at $\mathrm{C} / 5$ current rate between 0.002 and $1.5 \mathrm{~V}$.

\section{CONCLUSIONS}

This study reveals the use of $\mathrm{H}_{2} \mathrm{O}_{2}$ as an eco-friendly oxidant for the surface modification of NPG since the only by-product is water and the reaction is carried out at low temperature. FT-IR spectra and PXRD patterns indicates the formation of acidic groups or an oxidized layer without affecting the crystallographic structure of graphite due to mild oxidation. This film can act as an effective passivation film to prevent the decomposition of the electrolyte. In addition, thermogravimetric analysis and scanning electron microscopic images provided results suggesting that the oxidation eliminates some reactive structural defects in vein graphite. The d.c. electrical conductivity results indicated that the mild oxidation has not caused any adverse effect on the electrical conductivity of graphite. Oxidation of graphite with $\mathrm{H}_{2} \mathrm{O}_{2}$ resulted in a marked improvement of the electrochemical performance as anode materials for LIB. It is possible to conclude that the graphite material after the oxidation using $\mathrm{H}_{2} \mathrm{O}_{2}$ can be used as an 
anode material for LIB and this method is environmentally friendly and cost-effective method.

\section{REFERENCES}

Amaraweera, T.H.N.G., Balasooriya, N.W.B., Wijayasinghe, H.W.M.A.C., Attanayake, A.N.B., Dissanayake, M.A.K.L. and Mellander. B-E. (2018). Surface modification of natural vein graphite for the anode application in Li-ion rechargeable batteries. Ionics, 24: 3423-3429.

Amaraweera, T.H.N.G., Balasooriya, N.W.B. and Wijayasinghe, H.W.M.A.C. (2017). Study of thermal behavior of vein graphite for advance Technological applications. Journal of Geological Society of Sri Lanka, 18: 21-28.

Amaraweera, T.H.N.G., Balasooriya, N.W.B., Wijayasinghe, H.W.M.A.C., Attanayake, A.N.B., Dissanayake, M.A.K.L. and Mellander. B-E. (2014). Development of Sri Lankan natural vein graphite as anode material for Lithium-ion rechargeable batteries. Proceedings of the $14^{\text {th }}$ Asian conference on Solid State Ionics, Singapore, pp. 252-259.

Amaraweera, T.H.N.G., Balasooriya, N.W.B., Wijayasinghe, H.W.M.A.C., Attanayake, A.N.B. and Dissanayake, M.A.K.L. (2013). Purity enhancement of Sri Lankan vein graphite for lithium-ion rechargeable battery anode. Proceedings to $29^{\text {th }}$ Technical Sessions of Geological Society of Sri Lanka, pp.101-104.

Badenhorst H, Focke W. (2013). Comparative analysis of graphite oxidation behaviour based on microstructure. Journal of Nuclear Materials, 442: 75-82.

Balasooriya, N.W.B., Touzain, Ph. and Bandaranayake, P.W.S.K. (2006). Lithium electrochemical intercalation into mechanically and chemically treated Sri Lanka natural graphite. Journal of Physics and Chemistry of Solids, 67: 1213-1217.

Buqa, H., Würsig, A., Vetter, J., Spahr, M.E., Krumeich, F. and Novák, P. (2006). SEI film formation on highly crystalline graphitic materials in lithium-ion batteries. Journal of Power Sources, 153: 385-390.

Ein-Eli, Y. and Koch, V.R. (1997). Chemical Oxidation: A route to enhanced capacity in LiLon Graphite anodes. Journal of the Electrochemical Society 144: 2968-2973.
Fu, L.J., Liu, H., Li, C., Wu, Y.P., Rahm, E., Holze. $\mathrm{R}$, and $\mathrm{Wu}, \mathrm{H} . \mathrm{Q}$. (2006). Surface modifications of electrode materials for lithium ion batteries. Solid State Sciences, 8: 113-128.

Hewathilake, H.P.T.S., Karunarathne, N., Wijayasinghe, A., Balasooriya, N.W.B. and Arof, A.K. (2017). Performance of developed natural vein graphite as the anode material of rechargeable lithium ion batteries. Ionics, 23: 1417-1422.

Kurzweil, P., (2009) In: Encyclopedia of Electrochemical Power Sources; J. Garche, (Ed.) Amsterdam: Elsevier, 565-578.

Menachem, C., Wang, Y., Flowers, F., Peled, E. and Greenbaum, S.G. (1998). Characterization of lithiated natural graphite before and after mild oxidation. Journal of Power Sources, 76: 180-85.

Placke, T., Siozios, V., Schmitz, R., Lux, S.F., Bieker, P. and Colle, C. (2012). Influence of graphite surface modifications on the ratio of basal plane to "non-basal plane" surface area and on the anode performance in lithium ion batteries. Journal of Power Sources, 200: 83-91.

Touzain, P., Balasooriya, N., Bandaranayake, K. and Descolas-gros C. (2010). Vein graphite from the bogala and kahatagaha-kolongaha mines, Sri Lanka: a possible origin. The Canadian Mineralogist, 48: 1373-1384.

Wu, Y.P., Jiang, C., Wan, C. and Holze, R. (2003). Effects of pretreatment of natural graphite by oxidative solutions on its electrochemical performance as anode material. Electrochimica Acta, 48: 867-874.

Wu, Y.P., Jianga, C., Wana, C. and Holze, R. (2002). Modified natural graphite as anode material for lithium ion batteries. Journal of Power Sources, 111: 329-334.

Wu, Y.P., Jiang, C., Wan, C. and Holze, R. (2003). Effects of pretreatment of natural graphite by oxidative solutions on its electrochemical performance as anode material. Electrochim Acta, 48: 867-74.

Wissler, M. (2006). Graphite and carbon powders for electrochemical applications. Journal of Power Sources, 156: 142-150.

Xiaowei, L., Jean-Charles, R. and Suyuan, Y. (2004). Effect of temperature on graphite oxidation behavior. Nuclear Engineering and Design, 227: 273-280. 